\title{
KONFLIK ILLEGAL FISHING DI WILAYAH PERBATASAN INDONESIA-AUSTRALIA
}

\author{
Illegal Fishing Conflict at Indonesia-Australia Border Area
}

Oleh:

\author{
Akhmad Solihin $1^{*}$ \\ ${ }^{1}$ Direktur Eksekutif Ocean Watch Indonesi, Jl Puri Agung Mal Puri Indah, Jakarta 11610 \\ ${ }^{*}$ Korespondensi: akhmad_solihin@yahoo.com
}

Diterima: 8 Februari 2010; Disetujui: 23 Maret 2010

\begin{abstract}
The habits of Indonesian fisher who ride into the territory of the Australian fisheries often causing fluctuative relations between two countries, because repressive action of the Australian Government's apparatus. Therefore, the purpose of this study are: to assess the economic interest of fisher when get into the fishery regions of Australia, to analyze the offense of illegal fishing, and to get the eradication strategies of illegal fishing in two countries agreement areas. This study is a descriptive analysis, using a normative juridical approach which is equipped with comparative approaches. Based on the analysis yielded that 1) sea cucumbers and sharks are the main target of Indonesian fisher, wherein the value of profits from sea cucumbers of $A \cup \$ 14,000-A \cup \$ 30,000$, 2) illegal fishing violation occurred, i.e.; breach of the agreement not only operating areas, the utilization of fishery resources, environmental pollution, but also agents of illegal immigrants, 3) eradication of illegal fishing through the establishment of a legal approach by arbitration forming, and economic approach with alternative livelihoods development.
\end{abstract}

Key words: fisher, illegal fishing, the agreement.

\section{ABSTRAK}

Kebiasaan nelayan Indonesia memasuki wilayah perikanan Australia kerap menimbulkan pasang surut hubungan kedua negara, karena tindakan aparat Pemerintah Australia yang represif. Oleh karena itu, tujuan penelitian ini adalah mengkaji kepentingan ekonomi nelayan memasuki wilayah perikanan Australia, menganalisis pelanggaran illegal fishing, dan strategi pemberantasan illegal fishing di wilayah yang diperjanjikan kedua negara. Penelitian ini merupakan penelitian deskriptif analitis, yang menggunakan pendekatan yuridis normatif yang dilengkapi dengan pendekatan pendekatan komparatif. Berdasarkan analisa dihasilkan bahwa 1) teripang dan hiu adalah target utama nelayan Indonesia, dimana nilai keuntungan dari teripang sebesar AU\$ 14.000AU\$ 30.000 ; 2) pelanggaran illegal fishing yang terjadi yaitu pelanggaran terhadap perjanjian baik wilayah operasi, pemanfaatan sumber daya ikan, pencemaran lingkungan hidup, dan agen imigran gelap; 3) pemberantasan illegal fishing melalui pendekatan hukum dengan cara pembentukan arbitrase, dan pendekatan ekonomi dengan pengembangan mata pencaharian alternatif.

Kata kunci: nelayan, illegal fishing, perjanjian 


\section{PENDAHULUAN}

Perikanan dunia dihadapkan pada ancaman kelangkaan sumber daya. Hal ini sebagaimana yang diungkapkan Worm et al. (2006), bahwa pada tahun 2048 akan terjadi kehancuran perikanan global. Meski hasil penelitian Worm mendapatkan tentangan Branch (2008), karena dianggap mengabaikan berbagai faktor, salah satunya adalah regulasi internasional dan nasional dalam mewujudkan perikanan dunia yang berkelanjutan. Dilain pihak laporan $F A O$ (2008) mengungkapkan bahwa produksi perikanan tangkap dunia mengalami penurunan sejak tahun 2004.

Penurunan stok ikan selain disebabkan oleh alat penangkapan ikan yang semakin efisien, juga oleh tingginya sumbangan angka kegiatan illegal fishing. Gallic (2004) mengungkapkan bahwa kontribusi kegiatan illegal fishing mencapai 30\% dari total tangkapan dunia. Kegiatan illegal fishing selain merugikan secara ekonomi, merupakan ancaman bagi kelestarian sumber daya ikan.

Besarnya dampak yang ditimbulkan illegal fishing tersebut, menuntut berbagai negara menyusun kebijakan untuk mengatasinya. Salah satu negara yang serius mengatasi illegal fishing adalah Australia. Sebagai negara yang berbatasan dengan Australia, nelayan-nelayan yang berasal dari Indonesia kerap ditangkap oleh aparat pemerintah Australia dengan alasan telah melakukan illegal fishing di wilayah perikanannya.

Tujuan penelitian ini adalah memaparkan kepentingan ekonomi di perbatasan IndonesiaAustralia, illegal fishing di wilayah perbatasan dan hal-hal yang harus dilakukan kedua negara dalam melakukan pemberantasan illegal fishing di wilayah perbatasan tersebut.

\section{METODE PENELITIAN}

Metode penelitian ini adalah deskriptif analitis, yaitu penelitian yang mencari data atau gambaran seteliti mungkin mengenai obyek dari permasalahan (Soekanto, 1996). Gambaran tersebut berupa fakta-fakta mengenai permasalahan illegal fishing yang dilakukan nelayan Indonesia di wilayah perikanan Australia, yang dianalisis secara obyektif menurut hukum internasional di bidang perikanan yang dikaitkan dengan implementasi peraturan perundang-undangan nasional serta hal-hal yang harus dilakukan pemerintah untuk memberantas IUU fishing.

Penelitian ini menggunakan pendekatan yuridis normatif yang dilengkapi dengan pendekatan komparatif. Metode pendekatan yuridis normatif maksudnya penelitian ini menekankan pada ilmu hukum dan menitikberatkan pada pengumpulan data sekunder yang merupakan bahan-bahan hukum primer, sekunder dan tersier.

\section{HASIL DAN PEMBAHASAN}

\section{Kepentingan Ekonomi Perikanan di Perba- tasan}

Pemerintah Indonesia dan Australia telah melakukan perjanjian bilateral untuk mengatasi masalah perikanan tangkap di wilayah perbatasan. Berdasarkan penelusuran hukum, terdapat tiga perjanjian Indonesia-Australia yang membahas kegiatan nelayan pelintas batas, khususnya untuk nelayan tradisional. Ketiga perjanjian tersebut, yaitu: pertama, Memorandum of Understanding between the Government of Australia and the Government of the Republic of Indonesia Regarding the Operations of Indonesian Traditional Fishermen in Areas of the Australia Exclusive Fishing Zone and Continental Shelf, yang ditandatangani pada tanggal 7 November 1974.

Perjanjian pertama yang dikenal dengan istilah MOU BOX 1974 ini berisi aturan, diantaranya adalah: aturan pertama yang terkait dengan kegiatan yang diperbolehkan, yaitu: 1) yang diperbolehkan melakukan kegiatan penangkapan ikan di dalam wilayah perikanan Australia adalah nelayan-nelayan tradisional Indonesia yang menggunakan perahu tradisional; 2) kegiatan eksplorasi dan eksploitasi sumberdaya ikan di wilayah perikanan Australia dilakukan pada daerah-daerah yang berdekatan dengan Ashmore Reef, Cartier Islet, Scott Reef, Seringapatam Reef, dan Browse Islet; 3) nelayan tradisional diperbolehkan untuk mengambil air minum pada East Islet dan Midle Islet; dan 4) nelayan tradisional diperbolehkan mengambil: trochus (lola), beche de mer (teripang), abalone (simping), greensnail (siput hi-jau), spogens dan molusca (binatang lunak) lainnya, di dasar laut yang berdekatan dengan Ashmore Reef, Cartier Islet, Browse Islet, Scott Reef dan Seringapatam Reef.

Aturan kedua yang terkait dengan kegiatan yang dilarang, yaitu: 1) nelayan tradisional dilarang mendarat untuk mengambil air minum (air tawar) di luar dari daerah yang sudah ditetapkan; 2) nelayan tradisional dilarang untuk turun ke darat pada waktu berlindung diantara pulau-pulau sebagaimana disebutkan dalam perjanjian ini; (3) nelayan tradisional dilarang untuk menangkap dan mengambil penyu di wilayah perikanan Australia dan trochus (lola), beche de mer (teripang), abalone (simping), greensnail (siput hijau), spogens dan molusca (binatang lunak), pada daerah dasar laut dalam 
yang berbatasan dengan garis air tertinggi sampai ketinggian kontinen; dan 4) nelayan tradisional dilarang melakukan eksplorasi dan eksploitasi sumber daya alam hayati di landas kontinen, di luar dari pada yang ditetapkan dalam perjanjian ini.

Perjanjian kedua, Memorandum of Understanding between the Republic of Indonesia and the Government of Australia Concerning the Implementation of Provisional Fisheries Surveillance and Enforcement Arrangement. Perjanjian kedua yang yang berlangsung 27-29 Oktober 1981 ini disebabkan Pemerintah Australia mengumumkan wilayah perikanan pada 1 November 1979 dari 12 mil menjadi 200 mil. Hal yang sama dilakukan juga oleh Pemrintah Indonesia pada 21 Maret 1980 yang kemudian dikukuhkan dengan UU No. 5 Tahun 1983 tentang Zona Ekonomi Eksklusif Indone-sia.

Perjanjian kedua ini lebih menitikberatkan pada batas wilayah laut antara Indonesia dan Australia. Hal ini dikarenakan, nelayan-nelayan tradisional Indonesia masih banyak yang melakukan pelanggaran-pelanggaran di wilayah yang diperjanjikan. Untuk membatasi kegiatan para nelayan tradisional Indonesia, maka pada tahun 1983 Pemerintah Australia mengubah status peruntukan Ashmore Reef dari daerah yang diperbolehkan untuk penangkapan ikan menjadi kawasan taman nasional laut yang harus dilindungi, sehingga dilarang penangkapan jenis-jenis biota yang selama ini diperbolehkan ditangkap. Selain itu, nelayan hanya diperbolehkan mendarat untuk mengambil air tawar. Larangan Pemerintah Australia terhadap penangkapan ikan di Ashmore Reef termaktub pada "National Parks and Wildlife Conservation Act", dimana Australia mendeklarasikan "Ashmore Reef National Nature Reserve" pada 16 Agustus 1983.

Ketiga, Agreed Minutes of Meeting Between officials of Indonesian and Australia on Fisheries. Kesepakatan ketiga ini diselenggarakan pada tanggal 29 April 1989. Perjanjian ketiga ini merupakan petunjuk praktis pelaksanaan MOU BOX 1974 serta perubahan yang dilakukan pada perjanjian tahun 1981, sehingga kedua negara membicarakan hal-hal yang diatur dalam memorandum sebelumnya.

Hal-hal yang ditegaskan dalam Agreed Minute 1989 ini adalah: Pertama, perubahan status Ashmore Reef dan Cartier Islet yang tadinya merupakan bagian dari tempat para nelayan tradisional Indonesia beroperasi menjadi kawasan pelestarian alam. Kedua, terjadi penyusutan stok ikan di sekitar Ashmore Reef akibat aktivitas para nelayan tradisional Indonesia, oleh karena itu pihak Australia dikenakan kewajiban-kewajiban internasional tertentu untuk menjaga kelestarian alam pada wilayah Ashmore Reef dan Cartier Islet.

Ketiga, penegasan kembali keberadaan Indonesia dan Australia yang sama-sama menjadi anggota CITES. Keempat, atas tawaran pihak Australia, disepakati bahwa para nelayan tradisional Indonesia diperbolehkan melakukan penangkapan ikan tidak hanya di daerah-daerah yang berdekatan dengan Ashmore Reef, Cartier Islet, Scott Reef, Seringapatam Reef, dan Browse Islet sebagaimana ditetapkan dalam MOU BOX 1974, tetapi juga di daerah box yang lebih luas pada wilayah perikanan dan landas kontinen Australia, disamping melanjutkan terus pelaksanaan MOU BOX 1974 bagi nelayan tradisional yang beroperasi dengan menggunakan metode dan perahu-perahu tradisional.

Kelima, pihak Australia akan mengambil tindakan tegas terhadap para nelayan yang beroperasi di luar wilayah sebagaimana yang sudah ditetapkan dalam MOU BOX 1974. Kedua belah pihak sepakat untuk melakukan kerjasama dalam bidang perikanan untuk mengadakan mata pencaharian pengganti (alternative livelihood) bagi nelayan tradisional indonesia yang melakukan kegiatan penangkapan ikan berdasarkan MOU BOX 1974 di wilayah Indonesia bagian Timur. Keenam, kedua belah pihak juga sepakat untuk mempertimbangkan jenis-jenis satwa yang dilindungi melalui tukar menukar informasi agar menguntungkan kedua belah pihak. Ketujuh, akhirnya kedua belah pihak sepakat untuk berkonsultasi kapan saja diperlukan untuk menjamin efektivitas pelaksanaan MOU dan Agreed Minute yang ada.

Meskipun telah dilakukan perjanjian, namun nelayan-nelayan Indonesia kerap memasuki wilayah perikanan Australia, baik secara legal maupun ilegal. Hal ini didasari oleh kepentingan ekonomi masyarakat terhadap sumberdaya ikan di wilayah perbatasan. Hal ini sesuai perhitungan Fox dan Sen (2002), bahwa keuntungan yang diperoleh nelayan tradisional Indonesia dalam memanfaatkan teripang di wilayah MOU BOX 1974 untuk satu kali trip yang lamanya empat bulan, yaitu mendapatkan penghasilan maksimal AU\$30.000 dan minimal AU\$ 14.000 dengan nilai tukar yang berlaku pada saat itu 1 AU\$ sebesar Rp 5.000. Dengan kata lain, pendapatan satu trip kapal nelayan adalah maksimal $\mathrm{Rp} 150.000 .000$ dan minimal $\mathrm{Rp}$ 70.000 .000 (Tabel 1). Selain teripang, sirip ikan hiu adalah target nelayan Indonesia yang melakukan illegal fishing. Permasalahan illegal fishing di wilayah perbatasan didasarkan pada tingginya permintaan pasar terhadap teripang dan sirip ikan hiu. 
Tabel 1 Perkiraan Pendapatan Nelayan Tradisional Indonesia dalam Satu Kali Trip di Wilayah MOU BOX 1974

\begin{tabular}{lrr}
\hline \multicolumn{1}{c}{ Keterangan } & Maksimal & Minimal \\
\hline Jumlah Anak Buah Kapal (ABK) =12 & 1.500 & 1.000 \\
Hasil Tangkapan Teripang (kg) & 24 & 20 \\
Harga Jual Teripang per Ekor & 36.000 & 20.000 \\
Pendapatan Kotor & 6.000 & 6.000 \\
Total Biaya per Trip & 30.000 & 14.000 \\
Keuntungan Bersih (AU\$ / Trip) & 2.500 & 1.167 \\
Pendapatan Pemilik Kapal (Trip) & 2.500 & 1.167 \\
Pendapatan Pemilik Mesin (Trip) & 25.000 & 11.667 \\
Pendapatan Semua Nelayan ABK & 2.083 & 972 \\
Pendapatan Setiap Nelayan & 521 & 243 \\
Pendapatan Nelayan per Bulan & & \\
\hline
\end{tabular}

Sumber: Fox and Sen (2002)

Tabel 2 Jumlah Perahu Pelintas Batas yang tertangkap di Perairan Australia

\begin{tabular}{ccc}
\hline Tahun & Jumlah Perahu & Jumlah Nelayan \\
\hline 1975 & 3 & Tidak ada data \\
1980 & 2 & Tidak ada data \\
1985 & 5 & Tidak ada data \\
1987 & 1 & Tidak ada data \\
1988 & 46 & Tidak ada data \\
1989 & 29 & Tidak ada data \\
1990 & 43 & Tidak ada data \\
1991 & 38 & Tidak ada data \\
1992 & 15 & Tidak ada data \\
1993 & 23 & Tidak ada data \\
1994 & 111 & Tidak ada data \\
1995 & 76 & Tidak ada data \\
1996 & 97 & Tidak ada data \\
1997 & 122 & Tidak ada data \\
\hline
\end{tabular}

Sumber: Stacy (1999) diacu dalam Adhuri (2005)

Tabel 3 Jumlah Nelayan Indonesia yang Dideportasi dari Australia

\begin{tabular}{|c|c|c|c|c|c|c|}
\hline \multirow{2}{*}{ No. } & \multirow{2}{*}{ Asal Nelayan (Provinsi) } & \multicolumn{5}{|c|}{ Tahun } \\
\hline & & 2004 & 2005 & 2006 & 2007 & $2008^{1}$ \\
\hline 1. & Jawa Timur & 24 & 182 & 59 & - & - \\
\hline 2. & Nusa Tenggara Timur & 83 & 158 & 262 & 70 & 20 \\
\hline 3. & Sulawesi & 92 & 422 & 473 & 241 & 66 \\
\hline 4. & Maluku & 23 & 77 & 625 & 124 & 8 \\
\hline 5. & Papua & 65 & 116 & 495 & 199 & 14 \\
\hline 6. & Sumatera dan NTB & 9 & 57 & 151 & - & - \\
\hline & Jumlah & 296 & 1.012 & 2.065 & 653 & 108 \\
\hline
\end{tabular}

Ket: ${ }^{1}$ Data hingga 31 Maret 2008

Sumber: Alfiana (2008)

\section{Illegal Fishing di Perbatasan}

Nelayan Indonesia masih menjadikan wilayah perikanan Australia sebagai tempat potensial meskipun perjanjian bilateral telah ditandatangani,. Hal ini tercermin dari data tertangkapnya nelayan-nelayan Indonesia, baik tradisional maupun modern oleh aparat Pemerintah Australia. Pada Tabel 2 terlihat bahwa sejak tahun 1975 dengan pengecualian beberapa tahun, terdapat kecenderungan semakin meningkatnya jumlah perahu yang tertangkap. Tabel 3 juga memperlihatkan nelayan Indonesia yang dideportasi dari Australia.

Menurut Adhuri (2005), ada beberapa isu utama yang harus diketahui dalam memahami konflik illegal fishing yang terjadi di wilayah perbatasan Indonesia-Australia, yaitu: Pertama, Conflicting Claims. Hingga saat ini, masyarakat nelayan tradisional Indonesia, khususnya masyarakat nelayan dari Pulau Rote Nusa Tenggara Timur (NTT) menganggap bahwa fishing ground tertentu, khususnya Pulau Pasir (Ash- 
more Reef) adalah wilayah mereka. Klaim masyarakat NTT tersebut setidaknya didasarkan pada dua hal, yaitu: secara geografis, gugusan Pulau Ashmore letaknya jauh lebih dekat ke Pulau Rote di NTT sekitar 170 km, dari pada ke wilayah barat Darwin Australia yang jaraknya mencapai $840 \mathrm{~km}$ dan wilayah utara Broome Australia yang mencapai 610 km (Tanoni, 2008).

Secara historis, klaim masyarakat NTT terhadap Pulau Pasir didasarkan pada sejarah panjang aktivitas nelayan-nelayan di pulau ini. Menurut sejarah, jauh sebelum Kapten Samuel Ashmore menemukan Pulau Pasir dan Inggris mengklaimnya pada tahun 1878, sejak tahun 1602 masyarakat nelayan Indonesia secara de facto menguasai Pulau Pasir, karena pulau ini tempat mencari nafkah sekaligus tempat peristirahatan. Selain itu, kepemilikan Indonesia atas Pulau Pasir diperkuat juga oleh hasil kajian Yayasan Peduli Timor Barat yang menemukan studi McKnight (1976) serta studi Purwati (2005), bahwa menurut arsip Belanda diberitakan sesorang saudagar Tionghoa diberi izin pada tahun 1751 untuk mencari kulit penyu dari gugusan Pulau Pasir yang ada di selatan Pulau Timor. Dengan demikian, kegiatan perekonomian masyarakat Indonesia jauh lebih dulu dibandingkan dengan kedatangan Kapten Samuel Ashmore.

Kedua, pasar internasional sumber daya ikan. Faktor keberadaan pasar internasional ikut andil dalam mendorong aktivitas nelayannelayan tradisional Indonesia untuk melakukan penangkapan ikan di wilayah perikanan Australia. Hal ini dikarenakan, sumber daya yang ditangkap seperti teripang, trochus, dan sirip hiu bukan lah komoditas yang dikonsumsi secara langsung oleh mereka, melainkan untuk dijual ke luar negeri, yaitu pasar Cina.

Terkait dengan kegiatan illegal fishing, setidaknya terdapat lima pelanggaran yang umumnya terjadi di wilayah perbatasan Indonesia-Australia, yaitu (Songa, 2000): Pertama, pelanggaran terhadap wilayah operasi yang telah ditetapkan dalam MOU BOX 1974 dan Agreed minutes 1989. Pelanggaran ini merupakan pelanggaran terbanyak yang dilakukan oleh para nelayan tradisional Indonesia. Hal ini dikarenakan, sebagai akibat dari berubahnya peta wilayah kegiatan para nelayan tradisional Indonesia yang semula tunduk pada MOU BOX 1974 (Ashmore Reef, Cartier Islet, Scott Reef, Seringapatam Reef, dan Browse Islet) berubah sesuai dengan Agreed Minutes 1989 (Scott Reef, Seringapatam Reef, dan Browse Islet). Dengan kata lain, Ashmore Reef dan Cartier Islet dilarang untuk kegiatan pemanfaatan sumberdaya alam hayati.
Kedua, pelanggaran terhadap ketentuan yang berhubungan dengan pemanfaatan sumberdaya alam hayati sesuai dengan kesepakatan, baik sesuai MOU BOX 1974 maupun Agreed Minutes 1989. Salah satu jenis pelanggaran yang sering dilakukan oleh para nelayan tradisional Indonesia adalah pengambilan jenisjenis biota laut tertentu sebagai bagian dari sumber daya alam hayati yang dilarang, seperti pengambilan penyu dan burung beserta telurnya.

Ketiga, pelanggaran terhadap penggunaan fasilitas yang digunakan dalam kegiatan penangkapan ikan, dimana fasilitas tersebut tidak sesuai dengan apa yang telah ditetapkan melalui MOU BOX 1974 dan Agreed Minutes 1989. Pelanggaran ini terlihat dalam bentuk: melakukan kegiatan penangkapan dengan menggunakan perahu yang digerakkan oleh mesin (motor), menggunakan alat-alat penangkapan yang tergolong modern, bahkan menangkap ikan hiu dengan menggunakan gillnet.

Keempat, pelanggaran yang dilakukan berhubungan dengan masalah lingkungan hidup. Hal ini dapat terlihat antara lain dari tindakan para nelayan yang dapat menimbulkan kebakaran karena lalai memadamkan api setelah memasak atau membuang puntung rokok tanpa dimatikan terlebih dahulu apinya, ataupun kegiatan lain yang menyebabkan terkontaminasinya sumber-sumber air minum pada tempat-tempat dimana para nelayan diperbolehkan untuk mengambil air minum.

Kelima, pelanggaran lain yang juga sering dilakukan adalah pemanfaatan kegiatan penangkapan ikan ini sebagai sarana untuk mengantar dan memasukan imigran gelap ke Australia. Hal ini sesuai dengan pernyataan Kepala Biro Personalia Polda Nusa Tenggara Timur (NTT), Kombes Pol Drs Rochiyanto, bahwa patroli Angkatan Laut Australia yang menangkap nelayan Indonesia yang tengah mencari ikan di wilayah perairan sekitar Laut Timor dan wilayah perairan negeri Kanguru itu, karena sering menjadi agen imigran gelap untuk menyusup masuk ke wilayah negara tersebut (www.nttonlinel.com).

\section{Pemberantasan Illegal Fishing di Perba- tasan}

Kebijakan pemberantasan illegal fishing di wilayah perbatasan Indonesia-Australia harus memahami akar masalah terjadinya pelanggaran. Hal ini dikarenakan, kegiatan perikanan di wilayah tersebut sudah berjalan secara turun temurun. Adapun beberapa faktor terjadinya pelanggaran yang dilakukan oleh nelayan-nelayan tradisional Indonesia, yaitu (Songa, 2000): 
Pertama, pengertian nelayan terhadap MOU BOX 1974 maupun Agreed Minutes 1989 masih kurang. Hal ini disebabkan karena tingkat pendidikan mereka yang masih relatif rendah, sehingga sangat besar kemungkinan mereka tidak dapat membaca peta dan karenanya tidak dapat mengenali dengan tepat wilayah operasinya.

Kedua, nama pulau dan daerah yang disebut dalam MOU BOX 1974 maupun Agreed Minutes 1989, mungkin saja berbeda dengan nama yang dikenal sehari-hari oleh nelayan tradisional Indonesia. Seperti Pulau Pasir yang dinamakan Australia sebagai Ashmore Reef, Pulau Baru dinamakan Cartier Islet, dan Pulau datu dinamakan Seringapatam Reef.

Ketiga, para nelayan tradisional Indonesia kurang mengetahui batas wilayah yang disebut dalam MOU BOX 1974 maupun Agreed Minutes 1989 secara pasti. Hal ini terjadi karena, selain para nelayan tradisional tidak dapat membaca peta tetapi juga karena tidak terdapat tanda-tanda yang jelas yang menunjukan batas-batas sebagaimana yang dimaksudkan oleh MOU BOX 1974 maupun Agreed Minutes 1989. Sementara para nelayan tradisional pada umumnya tidak dilengkapi dengan peralatan navigasi yang memadai.

Keempat, hasil yang diperoleh dari usaha penangkapan cukup banyak atau cukup memuaskan sehingga para nelayan tidak ingin melakukan kegiatan di bidang usaha lain. Kelima, pengaruh faktor sosial dan budaya, dimana keluarga-keluarga tertentu dari masyarakat nelayan tradisional Indonesia asal Papela-Rote, setiap tahunnya mengadakan kunjungan ke makam leluhurnya yang meninggal dan dikuburkan di Pulau Pasir. Saat mengunjungi makam ini biasanya dilakukan bersama-sama dengan mencari hasil-hasil laut sebagaimana dilakukan oleh nenek moyangnya sejak beratus-ratus tahun yang lalu. Konsekuensinya dari kegiatan ini adalah bahwa nelayan tradisional Indonesia pasti memasuki wilayah konservasi alam Ashmore Reef, yang seyogyanya dilarang.

Kegagalan pemberantasan illegal fishing di wilayah perbatasan Indonesia-Australia disebabkan oleh pengabaian terhadap faktor-faktor diatas. Selain itu, penanganan pemberantasan illegal fishing tersebut lebih mengedepankan aspek hukum dan persuasif (Adhuri, 2005). Penanganan secara hukum yang dilakukan berdasarkan hukum Australia kurang efektif, karena masih banyak nelayan-nelayan tradisional Indonesia yang melakukan pelanggaran. Adapun kegiatan pengalihan mata pencaharian yang dilakukan Australian National University yang disponsori beberapa lembaga negara maupun LSM dari Australia belum menunjukan tingkat keberhasilan. Beberapa usaha alternatif yang dikembangkan adalah budidaya rumput laut, usaha pembesaran ikan kerapu, dan budidaya sponges. Tujuan dari program ini adalah menurunnya aktivitas pelanggaran kedaulatan nelayan-nelayan tradisional Indonesia di wilayah perairan Australia.

Kritikan terhadap cara-cara yang dilakukan selama ini sebagaimana yang disebutkan diatas adalah: Pertama, penanganan secara hukum. Penyelesaian hukum yang kerap mengusik rasa keadilaan yang menyebabkan ketersinggungan dan menyulut emosi kebangsaan, maka Pemerintah Indonesia dan Australia harus duduk bersama guna mendapatkan penyelesaian yang sifatnya win-win solution. Penyelesaian kasus nelayan tradisional Indonesia selama ini diselesaikan dengan proses peradilan telah menyebabkan pasang surut hubungan Indonesia-Australia.

Ada dua fenomena penting yang menarik mengenai penyelesaian per-soalan nelayan Indonesia di perairan Australia, yaitu: 1) bahwa putusan hakim Australia ku-rang efektif karena para nelayan Indonesia tidak jera untuk menghentikan kegiatannya dalam jurisdiksi teritorial Australia, dan 2) pemerintah Australia mengklaim bahwa kedatangan nelayan-nelayan Indonesia telah merugikan Pemerintah Australia dan orang asli aborigin (Thontowi, 2002).

Penuntasan sengketa ini perlu mengedepankan penyelesaian secara damai guna menciptakan perdamaian dan keamanan internasional sesuai dengan yang diamanatkan Pasal 33 ayat (1) Piagam PBB, yaitu negosiasi, penyelidikan dengan peraturan, konsiliasi, arbitrase, penyelesaian menurut hukum, melalui badan-badan atau perjanjian setempat, atau dengan cara damai lain yang dipilihnya sendiri. Untuk kasus pelanggaran perikanan nelayan Indonesia, Thontowi menyarankan alternatif penyelesaiannya melalui nonperadilan yang dalam hal ini adalah komisi arbitrase yang diharapkan mampu mengambil tanggung jawab bersama, sehingga baik secara moral maupun secara hukum internasional, kedua negara harus berusaha untuk menegakkan ketertiban dunia. Selain itu, dipilihnya komisi arbitrase dalam penyelesaian pelanggaran diyakini dapat menciptakan rasa keadilan dan menjauhkan ketersinggungan, mengingat kedua negara diwakili oleh masing-masing wasit atau arbiter.

Penyelesaian nonperadilan melalui komisi arbitrase Indonesia-Australia akan lebih akomodatif dan relevan serta mencerminkan kepentingan dua negara, meskipun bukan satu- 
satunya solusi alternatif. Hal ini dikarenakan, komisi arbitrase dapat berperan dalam mengeliminir tumpang tindih ketentuan hukum laut yang selama ini belum dapat dirumuskan. Tumpang tindih ketentuan hukum tersebut, yaitu perjanjian batas Landas Kontinen Indonesia Australia yang merujuk pada Konvensi Jenewa Tahun 1958 sedangkan perjanjian batas Zona Ekonomi Eksklusif yang merujuk pada UNCLOS 1982. Perbedaan penggunaan dasar aturan inilah yang menimbulkan tumpang tindih zona sehingga dikhawatirkan menimbulkan konflik dikemudian hari. UNCLOS 1982 mengatur wilayah ZEE dan Landas Kontinen tunduk pada aturan yang berbeda sesuai dengan rezim hukumnya masing-masing. Namun dalam perkembangan yang baru, penyelesaian batas maritim antara ZEE dan Landas Kontinen cenderung satu garis.

Kedua, alternative livelihood. Mengenai kebijakan alternative livelihood yang ditawarkan Australia perlu disikapi secara seksama, karena pengalihan mata pencaharian nelayan-nelayan tradisional dari status sebagai nelayan menjadi pembudidaya ikan dapat melemahkan eksistensi hak-hak perikanan tradisional. Padahal, status hak-hak perikanan tradisional (traditional fishing rights) sudah diakui dalam hukum internasional. Oleh karenanya, yang harus dilakukan oleh Pemerintah Australia dalam hal menjalin kerjasama, bukanlah bertujuan mengalihkan kegiatan para nelayan, melainkan memelihara dan melestarikannya sebagai suatu hak yang telah diakui oleh hukum internasional. Untuk itu, agar tidak terjadi pelanggaran, maka kegiatan yang seharusnya dilakukan oleh $\mathrm{Pe}$ merintah Australia adalah pengadaan fasilitas berupa alat navigasi dan fasilitas lain yang dapat membantu kegiatan para nelayan tradisional. Apabila hal ini diabaikan dan Pemerintah Australia hanya memfokuskan pada pengalihan mata pencaharian, berarti Pemerintah Australia bermaksud menghilangkan hak perikanan tradisional nelayan-nelayan Indonesia.

Disamping menuntut dibentuknya komisi arbitrasi untuk menyelesaikan kasus hukum pelanggaran kedaulatan, Pemerintah Indonesia harus menuntut pembangunan fasilitas navigasi agar tidak terjadi pelanggaran nelayan-nelayan tradisional Indonesia dalam melakukan kegiatan penangkapan ikan di wilayah yang diperjanjikan.

Hal lain yang juga diperhatikan Pemerintah Indonesia adalah pembahasan ulang perjanjian mengenai hak perikanan tradisional. Pada perjanjian MOU 1981 dan Agreed Minutes 1989, Pemerintah Australia secara sepihak merubah sebagian isi perjanjian MOU 1974, yaitu perubahan status Ashmore Reef sebagai kawasan pelestarian taman nasional sejak tahun 1983 serta pembatasan tangkapan biota laut. Hal ini dikarenakan, para ahli hukum dan Konvensi Wina tahun 1969 mengisyaratkan harus ada kesekapatan kedua pihak dalam melakukan perubahan terhadap isi perjanjian yang telah disepakati. Selain itu, dalam pembahasan ulang perjanjian tersebut harus menuntaskan pengertian nelayan tradisional, karena ketidakjelasan pengertian ini menyebabkan perbedaan penafsiran. Bruce dan Wilson dalam Thontowi (2002) menyatakan bahwa rumusan nelayan tradisional itu tidak tepat oleh karena mengandung kelemahan konseptual.

Menurut pengertian hak perikanan tradisional, ada empat yang harus diperhatikan, yaitu: 1) nelayan yang bersangkutan secara tradisional telah menangkap ikan di suatu perairan tertentu; 2) nelayan tersebut telah menggunakan alat-alat tertentu secara tradisional; 3) hasil tangkapan mereka secara tradisional adalah jenis ikan tertentu; dan 4) nelayan yang melakukan penangkapan ikan tersebut haruslah nelayan yang secara tradisional telah melakukan penangkapan ikan di daerah tersebut (Djalal, 1988).

Kriteria diatas juga menyimpan masalah yang menimbulkan ketidakjelasan, misalnya perbedaan istilah nelayan tradisional di Indonesia dengan di Australia. Apakah yang dikategorikan nelayan tradisional itu sama dengan nelayan kecil sebagaimana yang terdapat pada UU No. 45 Tahun 2009, bahwa nelayan kecil adalah orang yang mata pencahariannya melakukan penangkapan ikan untuk memenuhi kebutuhan hidup sehari-hari yang menggunakan kapal perikanan berukuran paling besar $5 \mathrm{GT}$.

\section{KESIMPULAN}

Indonesia dan Australia telah melakukan perjanjian bilateral sebanyak tiga kali, yaitu MOU 1974, MOU 1981, dan Agreed Minute 1989. Namun demikian, kegiatan pelanggaran lintas batas masih berlangsung dikarenakan adanya kepentingan ekonomi, yang diperkirakan keuntungan satu kali trip sebesar AU\$ 14.000 hingga $A \cup \$ 30.000$.

Pelanggaran yang umumnya terjadi di wilayah perbatasan Indonesia-Australia, yaitu: 1) pelanggaran terhadap wilayah operasi yang telah ditetapkan dalam perjanjian; 2) pelanggaran terhadap ketentuan yang berhubungan dengan pemanfaatan sumber daya alam hayati sesuai perjanjian; 3) pelanggaran terhadap penggunaan fasilitas penangkapan ikan; 4) pelanggaran yang dilakukan berhubungan dengan masalah lingkungan hidup; dan 5) pemanfaatan kegiatan penangkapan ikan yang 
digunakan sebagai sarana untuk mengantar dan memasukan imigran gelap ke Australia.

Pemberantasan illegal fishing di perbatasan Indonesia-Australia dapat ditempuh dua cara, yaitu aspek hukum melalui pembentukan arbitrase dalam penanganan hukum, dan aspek ekonomi melalui pengembangan mata pencaharian alternatif.

\section{DAFTAR PUSTAKA}

Adhuri, D.S. (Ed). 2005. Fishing In, Fishing Out: Memahami Konflik-konflik Kenelayanan di Kalimantan Timur dan Nusa Tenggara Timur. Jakarta. LIPI Press.

Alfiana. 2008. Sinkronisasi Nelayan Pelintas Batas Terkait MOU BOX 1974. Makalah disampaikan pada Workshop Sinkronisasi Masalah Nelayan Pelintas Batas Terkait MOU BOX 1974 pada 8-9 Mei 2008 di Surabaya.

Gallic, B.L. "Using Trade Measures in the Fight Against IUU: Opportunities and Challenges", makalah disampaikan pada IIFET 2004, Japan, 26-29 July 2004.

Branch, T.A. 2008. Not all Fisheries will be Collapsed in 2048. Marine Policy 32 (2008) 38-39.

Worm B, Barbier EB, Beaumont N, Duffy JE, Folke C, Halpern BS. 2006. Impacts of Biodiversity Loss on Ocean Ecosystem Services. Science 2006; 314:787-90.

Djalal, H. 1988. Perkembangan Hukum Nasional dalam Hubungannya dengan Hukum Laut Internasional. Makalah Terbatas Lemhanas.

FAO. 2008. the State of World Fisheries and Aquaculture 2008, Information Division, FAO, Rome, 2008.

Fox, J.J. and Sen, S. 2002. A Study of SocioEconomic Issues Facing Traditional Indonesia Fishers Who Access the MOU
Box: A Report for Environment Australia. Australia.

McChesney, A. 2003. Memajukan dan Membela Hak-Hak Ekonomi, Sosial dan Budaya. Yogyakarta. Insist Press.

McKnight, C.C. 1976. The voyage to Marege': Macassan Trepangers on Northern Australia. When did the Industry Begin?. Melbourne Univ. Press.

Purwati, P. 2005. Teripang Indonesia: Komposisi Jenis dan Sejarah Perikanan. Oseana, Vol. XXX Nomor 2, 2005: 11-18.

Soekanto, 1996. Pengantar Penelitian Hukum. Jakarta: Universitas Indonesia.

Songa, W.W. 2000. Pelaksanaan Perjanjian Antara Indonesia dan Australia tentang hak Perikanan Tradisional Dikaitkan dengan Nelayan Asal Nusa Tenggara Timur (Tidak Dipublikasikan). [Tesis]. Bandung. Program Studi Ilmu Hukum. Program Pascasarjana Universitas Padjadjaran.

Tanoni, F. 2008. Skandal Laut Timor : Sebuah Barter Politik-Ekonomi Canberra-Jakarta. Kupang: YPTB.

Thontowi, J. 2002. Hukum Internasional di Indonesia: Dinamika dan Implementasinya dalam Beberapa Kasus Kemanusiaan. Yogyakarta: Madyan Press.

Tribawono, D. 2002. Hukum Perikanan Indonesia. Bandung: PT. Citra Aditya Bakti.

Worm B, Barbier EB, Beaumont N, Duffy JE, Folke C, Halpern BS. 2006. Impacts of Biodiversity Loss on Ocean Ecosystem Services. Science 2006; 314:787-90.

www.nttonline.com. Nelayan Indonesia Sering Menjadi Agen Imigran Gelap. Diakses padahttp://www.nttonlinenews.com/ntt/id ex.php?view=article\&id=291\%3Anelayan -indonesia-sering-menjadi-agenimigran gelap\&option=com_content\&ltemid $=70$, tanggal 12 Juni $20 \overline{10}$. 